\title{
An explanatory model for the concept of mental health in
}

\section{Iranian youth [version 1; peer review: 1 approved with}

\section{reservations]}

\section{Ahdieh Chinekesh (D1,2, Seyed Ali Hosseini2, Farahnaz Mohammadi2, Mohammad Esmael Motlagh ${ }^{3,4}$, Monir Baradaran Eftekhari1 ${ }^{1}$ Shirin Djalalinia ${ }^{1,5}$, Gelayol Ardalan³}

\author{
${ }^{1}$ Social Determinant of Health Research Center, University of Social Welfare \& Rehabilitation Sciences, Tehran, Iran \\ 2Department of Research and Technology, Ministry of Health and Medical Education, Tehran, Iran \\ ${ }^{3}$ Department of Adolescents, Youth, and School Health, Bureau of Population, Family, and School Health, Ministry of Health and \\ Medical Education, Tehran, Iran \\ ${ }^{4}$ Department of Pediatrics, Ahvaz Jundishapur University of Medical Sciences, Ahvaz, Iran \\ ${ }^{5}$ Non communicable Diseases Research Center, EMRI, Tehran University of Medical Sciences, Tehran, Iran
}

V1 First published: $15 \mathrm{Jan} 2018,7: 52$

https://doi.org/10.12688/f1000research.12893.1

Latest published: 07 Feb 2018, 7:52

https://doi.org/10.12688/f1000research.12893.2

\section{Abstract}

Background: Mental health is considered as an integral and essential component of overall health. Its determinants and related factors are one of the most important research priorities, especially in adolescents and young people. Using a qualitative approach, the present study aimed to identify factors affecting the mental health of youth in Iran.

Methods: In 2017, following content analysis principles, and using semi-structured in-depth interviews, we conducted a qualitative study exploring the opinions of young people about mental health. A targeted sampling method was used, and participants were young volunteers aged 18 to 30 who were selected from Tehran province, Iran. Inclusion criteria for participants was willingness to participate in the study, and ability to express their experiences. Data collection was done with individual in-depth interviews. According to the explanatory model, the interviews were directed toward the concept of mental health and path of causality and auxiliary behaviors.

Results: 21 young adults participated, who met the study inclusion criteria, of whom 12 participants were male. Their mean age was 24.4 \pm 0.41 years and their education varied from primary school to Master's degree. Mental health was considered as mental well-being and a sense of satisfaction and efficacy, not only the presence of a disease or mental disorder. Based on the opinions of the interviewees, three factors of personal characteristics, family and society are involved in mental health. Individual factors were associated with behavioral and physical problems. One of the most important issues

\section{Open Peer Review \\ Approval Status \\ 1 \\ 2 \\ version 2 \\ (revision) \\ 07 Feb 2018 \\ version 1 \\ 15 Jan 2018

view \\ 1. Sara Esmaelzadeh Saeieh, Alborz University of Medical Sciences, Karaj, Iran \\ 2. Nourossadat Kariman (D), Shahid Beheshti University of Medical Sciences, Tehran, Iran}

Any reports and responses or comments on the article can be found at the end of the article. 
was revealed as tensions in societal and family conflicts. Economic problems and unemployment of young people were also extracted from the social factor.

Conclusion: In Iran, social factors such as jobs for the unemployed and job security are considered as important determinants in the mental health of young people.

Keywords

Mental health, youth, Explanatory model, Qualitative method, Iran

Corresponding author: Seyed Ali Hosseini (alihosse@gmail.com)

Author roles: Chinekesh A: Data Curation, Formal Analysis, Funding Acquisition; Hosseini SA: Project Administration, Supervision; Mohammadi F: Methodology, Project Administration, Supervision; Motlagh ME: Funding Acquisition; Baradaran Eftekhari M: Investigation, Methodology; Djalalinia S: Resources, Validation, Writing - Review \& Editing; Ardalan G: Visualization, Writing - Original Draft Preparation

Competing interests: No competing interests were disclosed.

Grant information: The present article is sponsored by the Health Deputy, Ministry of Health and Medical Education of Iran (grant no. 12292).

The funders had no role in study design, data collection and analysis, decision to publish, or preparation of the manuscript.

Copyright: $\odot 2018$ Chinekesh A et al. This is an open access article distributed under the terms of the Creative Commons Attribution License, which permits unrestricted use, distribution, and reproduction in any medium, provided the original work is properly cited.

How to cite this article: Chinekesh A, Hosseini SA, Mohammadi F et al. An explanatory model for the concept of mental health in Iranian youth [version 1; peer review: 1 approved with reservations] F1000Research 2018, 7:52 https://doi.org/10.12688/f1000research.12893.1

First published: 15 Jan 2018, 7:52 https://doi.org/10.12688/f1000research.12893.1 


\section{Introduction}

Mental health is a primary and principal component of health. Based on the definition of the World Health Organization, more than a lack of clinical mental illness, mental health is a sense of happiness that allows individuals to recognize their abilities, adapt to the natural tensions of life, and be efficient and productive resources for their communities ${ }^{1}$

Mental health and well-being are essential for our personal and social abilities as human beings to think, feel excitement, interact with each other, earn money, and enjoy life. Accordingly, promoting and maintaining mental health can be considered an important and vital concern for individuals, societies, and communities around the world ${ }^{2}$.

Many biological, social, and psychological factors influence the level and quality of health ${ }^{2}$. Based on recent evidence, more than 450 million people are suffering from some kind of mental disorder, and there are many psychological problems, around the world ${ }^{3}$.

Many studies have focused on mental health promotion. Jorum and Wright, in their study in Melbourne, showed that young people believe that interventions for preventions and control of mental disorders could be effective 4 . There was broad agreement from young people and their parents about what interventions are likely to be helpful and these views applied across the range of disorders presented. These interventions could be described as general and informal sources of help, rather than as specialist mental health services. The most negative views were about psychiatric medications and admission to hospital.

In 2007, Barry and Jenkins discussed the impacts of many community participation factors in promoting the mental health ${ }^{5}$. In 2012, Francesco and colleagues examined the role of supporting colleagues in the Clubhouse model using a qualitative method. Through this study, four peer support levels emerged and stressed that peer support would improve ${ }^{6}$.

In 2004, in Iran, Norbala and colleagues, using the General Health Questionnaire, showed that $21 \%$ of the total population suffered from mental illness (25.9\% of women and $14.6 \%$ of men) ${ }^{7}$. A related study in 2006 reported that about $2.2 \%$ of deaths in women and $1.2 \%$ of deaths in men could be attributed to mental disorders $^{8}$. In 2009, Ebadifard and colleagues conducted a semiexperimental study. The results of this study showed that educational intervention was influenced by attitudes and healthy behaviors in adolescent girls through belief, attitude, and mental and constructive factors 9 .

Considering the high prevalence of mental health disorders and also their importance and role in the development of related disease $^{10}$, it is necessary to design effective interventions to improvemental health. Many studies confirmed that improving mental health has considerable association with reducing community social harm ${ }^{11,12}$.
In the present study, we were interested in the mental health status of Iranian youth. To investigate this, we used the framework of the explanatory model ${ }^{13}$, which entails taking notes on a process, according to the concept of mental health, including causes and help-seeking behaviors. This model is mainly used to describe, organize, and manage determinants of welfare disorders ${ }^{14}$.

\section{Methods}

For this study, to understand the world from youth's perspectives and their experiences, and to uncover their lived worlds, we conducted individual interviews with young people ${ }^{15,16}$. We collected data from September 2016 to May 2017.

\section{Study participants}

Face-to-face in-depth interviews are an easy, flexible method for deeply understanding issues and are mostly used to collect data for explanatory studies ${ }^{17}$. In a qualitative study, the sample size is based on how many participants it takes to adequately answer the research question. With that aim, and considering the framework of the research question and purpose, the study time frame, and the available resources, we continued purposeful convenience sampling until the point of data saturation ${ }^{18}$ and no new categories, themes, or descriptions appeared.

Based on the inclusion criteria, we selected participants of different ages from 18 to 30 years old, from different regions of the city, and with different socioeconomic and cultural statuses, using the register list of students in Tehran city universities. We invited participants through their recorded email addresses. This selection was the method of randomization. If participants had not Iranian nationality or if they were beyond the determined age range, they were excluded.

Inclusion criteria for the participants were (a) willingness to participate in the study and (b) ability to describe their experiences.

\section{Interview guide}

The interview guide questions were designed by the scientific committee in accordance with the relevant literature and the study objectives. Toward our aim, we searched for related documents and focused on tools and measurement methods from different approaches. In these regards we searched the main international data bases, Scopus, PubMed and ISI/WOS. These databases cover most multidisciplinary related fields of research and we aimed to access similar studies and research tools. We searched for qualitative studies, research measurements, and guide questionnaires and qualitative questionnaires. The reliability and validity of guide questionnaires are been confirmed by the trust and accuracy that mainly is considered in qualitative research ${ }^{19}$.

We conducted a pilot study of semi-structured interviews with five young adults, including introducing the entry criteria, and based on the pilot study, we further developed the interview questions. These participants were selected from the universities of Tehran city. We used the list of the university register and then emailed to ask to participate. Young people focused more on the help seeking 
of mental health problems. After this pilot study we revised some components of interview guide, mostly for more clearance and consistency.

The main interview guide consisted of six semi-open questions that guided the interview process and data collection (Supplementary File 1).

\section{Interviews}

We collected the data for this study through deep, semi-structured, face-to-face interviews. At the beginning of the interviews, we explained the research goals and method to the participants. Each session lasted for 45-100 minutes (mean duration: 65 minutes). All interviews were conducted in peaceful environments such as special rooms of public libraries or parks with prior agreement of the participants.

Interviews began through general and open-ended questions developed based on the goals of the study, for example, "What are your mental health needs?"; "Can you tell about your experiences of mental well-being?" or "What obstacles have stopped you from having mental health?" The interviews then continued with exploratory questions to clarify the concept and obtain more in-depth information. All conversations were audio recorded with the participants' permission.

\section{Data analysis}

We performed content analysis of the data collected from the in-depth interviews, ${ }^{20}$ all of which had been transcribed. To facilitate data analysis, we used Dedoose (version 7.6.6; categorization, constant comparisons, and quotation retrieval). This web-based application, developed at UCLA, is mostly used for analyzing data in qualitative research ${ }^{21}$.

We read the transcripts to extract the "meaning units." The coding scheme was theoretically consistent with the context of the study framework, with regard to the concept of mental health including causes and help-seeking behaviors. We extracted the themes and subthemes from the transcripts to generate new codes or modify codes by induction, and we categorized the inductive codes into meaningful topics ${ }^{22}$.

\section{Trustworthiness}

Trustworthiness in qualitative research has been divided into credibility, dependability, conformability, and transferability ${ }^{23-30}$. In this study, we established credibility through the main researcher's (AC, SAH) prolonged engagement with the subject matter and triangulation of data sources (interviews with youths).

We performed member checking by presenting each interviewee with a summary of the interview to check for accuracy. To address the issues of dependability and conformability throughout the entire research process, the main and local supervisors (Ahdieh Chinekesh, Seyed Ali Hosseini, Shirin Djalalinia) reviewed an audit trail of translated transcripts, related documents for data analysis, and member opinions. For transferability, a complete set of data analysis documents is available on request. This access to the research trail allows other researchers to share the results of this research with others or to repeat the research as closely as possible ${ }^{28-30}$.

\section{Ethical considerations}

The study was approved by the University of Social Welfare and Rehabilitation Sciences Ethics Committee in Tehran, Iran (IR.USWR.REC.1395.378). Participation in the study was voluntary, participants were ensured that they could withdraw from the study whenever they wanted, and we obtained written informed consent from all participants. At the beginning of the interviews, we explained the study research goals and methods to the participants and assured them of the confidentiality of the information. We respected the study ethical considerations, including data collection (recording and duplicating interviews), data analysis, and dissemination of results. We collected all information anonymously and used the results only for research purposes.

\section{Results}

The participants consisted of 21 young adults who met the study inclusion criteria; among these, 12 participants were male. The participants' mean age was $24.4 \pm 0.41$ years, and their education varied from primary school to master's degrees. All participants resided in Tehran, although from different geographic regions of Tehran. Table 1 shows the participants' demographic characteristics.

The results were analyzed under the following themes and subthemes:

\section{Definition of mental health}

The majority of participants believed that mental health is an inner emotional feeling of happiness. They stated that inner peace and satisfaction are among the most important signs of mental health. According to the participants, people who have high self-esteem and who are determined, tolerant, and realistic are satisfied.

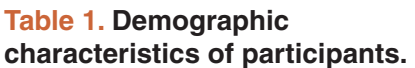

\begin{tabular}{|c|c|}
\hline Characteristics & N (\%) \\
\hline $\begin{array}{l}\text { Sex } \\
\text { Female } \\
\text { Male }\end{array}$ & $\begin{array}{l}9(43) \\
12(57)\end{array}$ \\
\hline $\begin{array}{l}\text { Grade } \\
\text { Diploma } \\
\text { Bachelor } \\
\text { Master degree }\end{array}$ & $\begin{array}{l}7(33) \\
8(38) \\
6(29)\end{array}$ \\
\hline $\begin{array}{l}\text { Occupation } \\
\text { Unemployed } \\
\text { Worker* } \\
\text { Employee* } \\
\text { Student }\end{array}$ & $\begin{array}{l}3(14) \\
4(19) \\
6(29) \\
8(38)\end{array}$ \\
\hline Total & $21(100)$ \\
\hline \multicolumn{2}{|c|}{$\begin{array}{l}\text { Employee: A person who is } \\
\text { employed in the public sector; } \\
\text { Worker: a person who works for a } \\
\text { private sector and operates under an } \\
\text { annual contract. }\end{array}$} \\
\hline
\end{tabular}


Based on the experiences of young people, good mental health cannot be recognized solely by the absence of illnesses and mental disorders such as depression or anxiety. Mental health is also the ability to adapt to one's environment and surroundings. The participants in this study stated that mental health entailed having healthy individual and social functioning and that it includes skills such as coping, problem solving, communication skills, and stress management.

\section{Causal pathway of mental health problems}

We classified the subthemes of the causes of mental health problems as social, family or personal.

\section{A. Social factors}

Most participants said unemployment or low-income employment was a major contributor to mental health problems. Unemployment, especially in men, lead to financial problems. On the other hand job insecurity is one of the main sources of stress. People who are unemployed or have low-income jobs are less likely to have mental well-being than do people who are gainfully employed, and they show higher rates of violence, anxiety, aggression, and depression $^{31}$.

Young people included in this study were pointed out as having a bright future and reported marital problems and the tendency towards high-risk behaviors as important outcomes of unemployment.

Young people in this study highlighted that unemployment, lack of income and lack of entrepreneurship among young people lead to frustration and disappointment. The majority of participants noted the great attention by the authorities to creating jobs.

'If you are unemployed, you need to worry about your future and your living costs. Planning for the future is impossible. You'll be disappointed after a while.' (Boy, 26, single, bachelor's degree)

'I am looking for a job so I can buy a house and a car.' (Boy, 23, single, diploma)

'Most young people have no hope of finding right job.' (Girl, 24, single, bachelor's degree)

Young people in this study noted that having a job would prevent high-risk behaviors:

"The constant presence of young people in the park is due to their unemployment, lead them to cigarettes and other tobacco products". (Boy, 27, single, master's degree)

Young people pointed to having enough income:

"Having a job with enough income is one of the most important priorities of mental well-being." (Girl, 26, married, bachelor's degree)
"Our problem is that we do not have a good salary system that has enough incentive work. When I started working for the first time, my salary was very low. I was disappointed, and I realized that I had to work two shifts". (Boy, 30, married, master's degree)

Some young people pointed to gender discrimination in finding work:

"Girls have less chance than boys for getting a job". (Girl, 24, single, bachelor's degree)

Some young people expressed lack of confidence in the future as one of the most important factors in the lack of mental relaxation:

"Society cannot provide this peace of mind for young people who, after completing their course, will find the right work, and we do not have a vision for the future". (Boy, 26, single, master's degree)

The most important issue raised by the young people was that economic problems lead to marital problems:

"The lack of economic security in society and inflation have an important impact on the issue of marriage. My marriage has been destroyed by economic problems for five years, and we both are still engaged, we cannot solve our economic problems". (Boy, 30, married, bachelor's degree)

\section{B. Familial factors}

Some participants believed that lack of understanding and coherence in the family, lack of parental attention to young people's needs, and tension in families such as parental violence can cause emotional difficulties and behavioral problems in children. The participants described the existence of disputes and differences between parents as influences on social security and the need for mental health services. The participants also stated that healthier, more secure family environments have positive effects on family members' morale and that these favorable effects transfer to society.

'Controversy between parents makes me feel dizzy. When I go out of the house after my parent's dispute, I feel like strangers. I feel like I'm separated. It's very sad.' (Boy, 22, single, bachelor's degree)

'Our parents are our supporters, and when they fight and threaten each other, I get tired of life.' (Girl, 19, single, diploma)

'I'm always worried, sometimes my mother speaks and suddenly everything goes wrong and there are arguments and arguments... I leave the house.' (Boy, 20, single, university student)

The young people referred to factors such as high expectations and disobedience as causes of differences in families:

'Sometimes the expectations are too much. The main problem is that everyone has expectations from others, but they do not 
care what others expect from them. People think they have done well but have not seen anyone good.' (Boy, 24, single, diploma)

Relationships between family members also affect mental health. Study participants reported the existence of autarchy in the family in the form of patriarchy or matriarchy or collaborative decisionmaking and respect for the opinions of all family members as the two main types of families:

'I learned from childhood to consult, because all decisions in our family are made in consultation with family members.' (Boy, 21 , single, university student)

'In my family, my dad made all the decisions alone and did not consult with family members. Now I am married, but I have no ability to make decisions and I feel that I should obey my husband's decisions.' (Girl, 26, married, diploma)

A large number of participants stated that the choice of spouse and the age of marriage played a role in promoting mental health:

'As you grow older, making a decision on marriage is harder, and choosing is difficult.' (Girl, 25, single, master's degree)

\section{Individual factors}

According to some participants, behavioral characteristics such as aggressiveness, lying, selfishness, jealousy, pride, irresponsibility are important in mental health problems. From the young people's perspectives in this study, mentally relaxing requires "managing anger and anxiety" and "gaining happiness" and "hoping for a bright future."

Most participants stated that forgiveness, patience, anger control, and positive thinking are important for the mental health of young people. Acquiring emotion management skills, especially controlling anger and anxiety, was one of the most common and important mental health needs the young people discussed:

'We must not be angry in the tensions of life... learn to be calm. '(Girl, 22, single, university student)

'The anger in our society is too much. People argue with each other in accidents.' (Boy, 24, single, diploma)

They also said that exercise is beneficial for mental health:

'When exercising, the person feels less jealous and humiliated. As a result, he has better mental health.' (Girl, 21, single, university student)

\section{Help seeking}

Help seeking can refer to seeking counseling, having social support, or "strengthening the faith in God." Participants stated that social support is important in personality development and mental health promotion, and they reported receiving social support from various sources such as parents and family members, peers, spouses, and community members. Participants suggested that engaging with friends and peers in activities such as entertainment, hobbies, traveling, and social gatherings were all effective strategies for changing the rhythm of life and facing depression:

'If I have a problem I will share with my mother. She understands me and is my best friend.' (Girl, 21, single, university student)

'When I'm sad, I want to be with my friends. They help me and try to understand me.' (Boy, 24, single, university student)

Most participants referred to the role of religion in achieving peace of mind. These young people reported that they believed in God as a "safe beach" that could be trusted:

'When I'm sad, I want help from God. I believe in the existence of a supernatural power, and he helps me.' (Girl, 21, single, university student)

Most of the young participants in this study recommended learning life skills and communication skills, stating that skills such as stress management, problem solving, and decision-making are effective ways to promote mental health. Participants also recommended counseling during psychological crises, as well as herbal medicines, exercise, and travel as coping strategies:

'I think we need to learn how to manage our daily stress, learn the ability to solve a problem, learn communication skills, and learn how to say no. These should be in the form of courses at the school or university for young people.' (Girl, 24, single, bachelor's degree)

Although most participants believed in counseling and its benefits, they did note that the cost was a primary barrier to seeking counseling services:

'I got help from a psychologist, but because of the high cost, I could not continue.' (Boy, 21, single, University student)

\section{Discussion}

This was a qualitative study on the perceptions of young people in Tehran about mental health; most participants in this study equated mental health with mental well-being. Based on the results, mental health problems are caused primarily by social, individual, and family factors. Based on the participants' comments, by controlling daily stress with the help of family and friends, you can manage mental problems at an early stage, but in acute cases, it is necessary to get help from psychologists. The participants also referred to the important role of religion in mental well-being.

The definition of mental health highlights mental well-being. Individuals with good mental health can recognize their abilities, cope with the everyday stress and challenges in life and participate effectively in society ${ }^{32}$. Health is a multidimensional concept that, in addition to lack of illness and disability, also involves a sense of 
happiness and well-being ${ }^{33}$, and the results of this study indicate that many young people are trying to explain mental health positively. They referred to feelings of happiness, hope for the future, and spirituality, which are among the most important indicators of positive mental health ${ }^{34}$. In various studies, there is a significant relationship between mental health and positive psychological factors such as happiness, hope, and spirituality ${ }^{35-40}$.

Our study also showed that most youth attributed mental health to external factors in their social worlds, which was consistent with other studies of participants in Australia, Japan, and Kenya who believed in social causes of poor mental health such as difficult life events and circumstances, financial problems, and traumatic events $^{41-43}$. Mental health problems can also be triggered by social circumstances ${ }^{44}$.

In our results, the young participants perceived psychological symptoms as transient reactions to external stressors. Therefore, young people should receive appropriate training on symptoms of mental illness to be able to recognize mental disorders according to symptoms. In addition, differing approaches to treatment could help professionals to choose appropriate and effective therapies for young people.

We also found that economic problems were one of the main causes of poor mental health among the young people in our study. Unemployment and lack of job security cause young people stress and increased tensions related to work, which negatively affect the mental health of young people ${ }^{45}$. Based on the project COS-RGO, in the field of mental health and economic development, economic changes can increase mental health problems ${ }^{46}$. Moreover, the results of a national project in Iran showed that economic growth and income inequality among economic variables had the most impact on mental health ${ }^{47}$.

Among families, the relationship between parents, tensions in the family environment, and divorce affect the mental health of family members ${ }^{48}$. A multi-method study in the UK showed that parental divorce had a negative effect on adult mental health ${ }^{48}$. Individual negative traits such as jealousy have been linked with low self-esteem. These behaviors refer to negative thoughts and sense of insecurity, worry, and anxiety ${ }^{49}$.

The results of this study indicate that help seeking begins with limiting daily stress and that resources such as social support from friends and family and counseling facilitate this process. In this context, religious beliefs are shown to have an important role in achieving peace of mind; reinforcing faith in God has been highlighted as one of the most important sources of peace. Levin et al. conducted a study of African Americans in 2005 and found that religion affected physical and mental health ${ }^{50}$.

As its main strength, we used for this study a well-developed methodology through which we extracted saturated data from in-depth interviews and analyzed the data precisely based on the defined protocol. During the study, we encountered some restrictions, such as the lack of cooperation of some of the invited participants, the diversity of participants' perceptions, and the limitations in generalizing the results.

Given the above, we suggest designing and evaluating participatory interventions for mental health promotion for future studies. Given the strategy outlined, further research on the determinants of mental health in young people in different populations is recommended.

\section{Conclusion}

In Iran, social factors such as jobs for the unemployed and job security for workers have essential roles in youth mental health. Based on the findings of this study, to promote mental health in young people, we propose participatory strategies. In this regard, the youth as a target group will engage with policy makers and researchers to design, develop, and implement mental health programs.

\section{Data availability}

Transcripts of the 21 interviews performed with young people (in Persian) are available on request from the corresponding author (alihosse@gmail.com).

\section{Competing interests}

No competing interests were disclosed.

\section{Grant information}

The present article is sponsored by the Health Deputy, Ministry of Health and Medical Education of Iran (grant no. 12292).

The funder had no role in study design, data collection and analysis, decision to publish, or preparation of the manuscript.

\section{Acknowledgments}

The present paper is based on a PhD thesis led by the University of Social Welfare and Rehabilitation Sciences of Tehran and with the financial support of the Deputy of Health, Ministry of Health and Medical Education of Iran. We appreciate the professors of the University of Social Welfare and Rehabilitation Sciences of Tehran, who provided necessary assistance in conducting this research.

\section{Supplementary material}

Supplementary File 1: Interview guide. 
1. World Health Organization (WHO): Investing in mental health. Geneva. 2003 Reference Source

2. World Health Organization (WHO): Mental health: strengthening our response (Fact sheet No. 220). Geneva, Switzerland; 2010; 68-9.

Reference Source

3. Burgermeister D, Kwasky A, Groh C: Promoting mental health concepts in a doctor of nursing practice curriculum: an integrated and global approach. Nurse Educ Pract. 2012; 12(3): 148-152.

PubMed Abstract | Publisher Full Text

4. Jorum AF, Wright A: Beliefs of young people and their parents about the effectiveness of interventions for mental disorders. Aust N Z J Psychiatry. 2007; 41(8): 656-66.

PubMed Abstract | Publisher Full Text

5. Barry MM, Jenkins R: Implementing Mental Health Promotion. Philadelphia, USA: Churchill Livingstone. 2007.

Reference Source

6. Coniglio F, Hancock N, Ellis L: Peer support within Clubhouse: a grounded theory study. Community Ment health J. 2012; 48(2): 153-60.

PubMed Abstract | Publisher Full Text

7. Noorbala AA, Bagheri Yazdi SA, Yasami MT, et al:: Mental health survey of the adult population in Iran. Br J Psychiatry. 2004; 184(1): 70-73.

PubMed Abstract | Publisher Full Text

8. Hughes JR: Should criteria for drug dependence differ across drugs? Addiction. 2006; 101(Suppl 1): 134-41

PubMed Abstract | Publisher Full Text

9. Ebadifard AF, Solhi M, Roudbari M, et al: Survey the effect of educational intervention through the BASNEF model on preventive behaviors according to mental health in girl adolescents. J Guilan Univ Med Sci. 2010; 19(73) 20-29.

Reference Source

10. Brown S, Inskip H, Barraclough B: Causes of the excess mortality of schizophrenia. Br J Psychiatry. 2000; 177(3): 212-17. PubMed Abstract | Publisher Full Text

11. Mohammadi F, Eftekhari MB, Dejman M: Seeking comfort: women mental health process in I. R. Iran: a grounded theory study. Int J Prev Med. 2014; 5(2): 217-23. PubMed Abstract | Free Full Text

12. Anderson J, Huppert F, Rose G: Normality, deviance and minor psychiatric morbidity in the community. A population-based approach to General Health Questionnaire data in the Health and Lifestyle Survey. Psychol Med. 1993; 23(2): 475-85

PubMed Abstract | Publisher Full Tex

13. Kleinman A: Culture and depression. N Engl J Med. 2004; 351(10): 951-3. PubMed Abstract | Publisher Full Text

14. Stuifbergen AK, Seraphine A, Roberts G: An explanatory model of health promotion and quality of life in chronic disabling conditions. Nurs Res. 2000; 49(3): 122-9

PubMed Abstract | Publisher Full Text

15. Kvale S: InterViews: An Introduction to Qualitative Research Interviewing Thousand Oaks, Sage. California. 1996.

Reference Source

16. Dahlgren L, Emmelin M, Winkvist A: Qualitative methodology for internationa public health. Department of Public Health and Clinical Medicine, Umea University Umea. 2007

Reference Source

17. Boyce $\mathrm{C}$, Neale $\mathrm{P}$ : Conducting in-depth interviews: $A$ guide for designing and conducting in-depth interviews for evaluation input. Pathfinder International Watertown, MA; 2006; 6-10.

Reference Source

18. Patton MQ: Qualitative evaluation and research methods. (3rd Ed.). Newbury Park CA: Sage Publications. 2001.

Reference Source

19. Flick U: An Introduction to Qualitative research. (3rd Ed.). Sage Publication LTD. 2006

Reference Source

20. Hsieh HF, Shannon SE: Three approaches to qualitative content analysis. Qual Health Res. 2005; 15(9): 1277-88.

PubMed Abstract | Publisher Full Text

21. Dedoose introduction. 2017; [Last accessed on 2017 Aug. 21] Reference Source

22. Graneheim UH, Lundman B: Qualitative content analysis in nursing research: concepts, procedures and measures to achieve trustworthiness. Nurse Educ Today. 2004; 24(2): 105-12.

PubMed Abstract | Publisher Full Text

23. APA: Diagnostic statistical manual of mental disorders (DSM-IV). American Psychiatry association, Washington C. 2000.

Reference Source
24. Maruish M: The Use of Psychological Testing for Treatment Planning and Outcomes Assessment: Instruments for Adults. Lawrence Erlbaum Associates. 2004.

Reference Source

25. Kleinman A: Concepts and a model for the comparison of medical systems as cultural systems. Soc Sci Med. 1978; 12(2B): 85-92.

PubMed Abstract | Publisher Full Text

26. Okello ES, Neema S: Explanatory Models and Help-Seeking Behavior: Pathways to Psychiatric Care Among Patients Admitted for Depression in Mulago Hospital, Kampala, Uganda. Qual Health Res. 2007; 17(1): 14-25. PubMed Abstract | Publisher Full Text

27. Dejman M, Ekblad S, Forouzan AS, et al.: Explanatory Model of Help-Seeking and Coping Mechanisms among Depressed Women in Three Ethnic Groups of Fars, Kurdish, and Turkish in Iran. Arch Iran Med. 2008; 11(4): 397-406. PubMed Abstract

28. Elo S, Kyngas $\mathrm{H}$ : The qualitative content analysis process. J Adv Nurs. 2008 62(1): 107-15

PubMed Abstract | Publisher Full Tex

29. Lincoln YS, Guba EG: Naturalistic inquiry. Beverly Hills, CA: Sage. 1985. Reference Source

30. Mays N, Pope C: Qualitative research in health care. Assessing quality in qualitative research. BMJ. 2000; 320(7226): 50-52. PubMed Abstract | Publisher Full Text | Free Full Text

31. Archer J, Rhodes V: Bereavement and reactions to job loss: a comparative review. Br J Soc Psychol. 1987; 26(Pt 3): 211-24.

PubMed Abstract | Publisher Full Tex

32. Greenberg J: Comprehensive Stress Management. 12th Edition, McGraw-Hill Humanities/Social Sciences/Languages@2006.

33. Poursardar F, Sangari A, Abbaspour Z, et al:: The Effect of Happiness on Mental Health and Life Satisfaction: A psychological model of well-being J Kermanshah Univ Med Sci. 2012; 16(2): 139-147. Reference Source

34. Ebrahimi A, Aarabi S, Khaluei MM: Comparing the Mental Health and Some Positive Psychologic Factors Including Happiness, Hope and Spirituality among Students of Medicine in Isfahan University of Medical Sciences, Iran, during Years of Education. J Isfahan Med Sch. 2014; 31(261): 1885-96. Reference Source

35. Jafari E, Dehshiri GR, Eskandari $\mathrm{H}$, et al:: Spiritual well-being and mental health in university students. Procedia Soc Behav Sci. 2010; 5: 1477-81. Publisher Full Text

36. Koenig HG, McCullough ME, Larson DB: Handbook of religion and health. Oxford, UK: Oxford University Press. 2000. Reference Source

37. Rew L, Wong YJ: A systematic review of associations among religiosity/ spirituality and adolescent health attitudes and behaviors. $J$ Adolesc Health 2006; 38(4): 433-42.

PubMed Abstract | Publisher Full Text

38. Alberktsen G: Happiness and related factors in pregnant women Developmen of psychiatrist. Bangkok, Thailand: Faculty of Median, Chulalongkorn University. 2003.

39. Perneger TV, Hudelson PM, Bovier PA: Health and happiness in young Swiss adults. Qual Life Res. 2004; 13(1): 171-8. PubMed Abstract | Publisher Full Text

40. Rodriguez-Hanley A, Sunder CR: The demise of hope: On losing positive thinking. In: Handbook of hope: Theory, measures, and applications. Snyder CR, editor. San Diego CA: Academic Press. 2000; 39-54. Publisher Full Text

41. Cinnirella M, Loewenthal KM: Religious and ethnic group influences on beliefs about mental illness: a qualitative interview study. Br J Med Psychol. 1999; 72(Pt 4): 505-24.

PubMed Abstract | Publisher Full Text

42. Lawrence V, Murray J, Banerjee S, et al:: Concepts and causation of depression: a cross-cultural study of the beliefs of older adults. Gerontologist. 2006; 46(1): 23-32.

PubMed Abstract | Publisher Full Text

43. Nakane $\mathrm{Y}$, Jorm AF, Yoshioka K, et al.: Public beliefs about causes and risk factors for mental disorders: a comparison of Japan and Australia. BMC Psychiatry 2005; 5(1): 33

PubMed Abstract | Publisher Full Text | Free Full Text

44. WHO: Gender in Mental Health Research. Department of Gender, Women and Health Family and Community. World Health Organization, Geneva, 2004; 14-19, 7-9. Reference Source

45. Paul KI, Moser K: Unemployment impairs mental health: Meta-analyses. $J$ Vocat Behav. 2009; 74(3): 264-82.

Publisher Full Text 
Herrman H, Saxena S, Moodie R: Promoting mental health: concepts, emerging evidence, practice, a report of the World Health Organization. 2005 Reference Source

47. Mehregan N, Ghasemifar S, Sohrabivafa $\mathrm{H}$, et al.: The impact of economic and social conditions on mental health the provinces of Iran (1378-1391). Q Parliament Strat. 2016; 23(85): 85-106. Reference Source

48. Chase-Lansdale $P$, Cherlin AJ, Kiernan KE: The long-term effects of parental divorce on the mental health of young adults: a developmental perspective.
Child Dev. 1995; 66(6): 1614-34.

PubMed Abstract | Publisher Full Text

49. Johnson RJ, Kaplan HB: Gender, aggression, and mental health intervention during early adolescence. J Health Soc Behav. 1988; 29(1): 53-64.

PubMed Abstract | Publisher Full Text

50. Levin J, Chatters LM, Taylor RJ: Religion, health and medicine in African

Americans: implications for physicians. J Natl Med Assoc. 2005; 97(2):

$237-49$.

PubMed Abstract | Free Full Text 


\section{Open Peer Review}

\section{Current Peer Review Status: ?}

\section{Version 1}

Reviewer Report 23 January 2018

https://doi.org/10.5256/f1000research.13975.r29804

(c) 2018 Saeieh S. This is an open access peer review report distributed under the terms of the Creative Commons Attribution License, which permits unrestricted use, distribution, and reproduction in any medium, provided the original work is properly cited.

\section{Sara Esmaelzadeh Saeieh}

Social Determinants of Health Research Center, Alborz University of Medical Sciences, Karaj, Iran

Please correct grammar in the paper

Please provide further details about time of sampling, situation and environment of the interview. Who is doing the interview?

Was the interviewer an expert?

We suggest that results of qualitative study include theme (category) sub them (sub category) and codes of study are mentioned in table.

Please omit extra explanation about methods and only mention the methods of your study.

Please explain about the type of content analysis.

Is the work clearly and accurately presented and does it cite the current literature?

Yes

Is the study design appropriate and is the work technically sound?

Yes

Are sufficient details of methods and analysis provided to allow replication by others? Yes

If applicable, is the statistical analysis and its interpretation appropriate?

Yes

Are all the source data underlying the results available to ensure full reproducibility? Yes

Are the conclusions drawn adequately supported by the results? Yes

Competing Interests: No competing interests were disclosed. 
Reviewer Expertise: Reproductive health

I confirm that I have read this submission and believe that I have an appropriate level of expertise to confirm that it is of an acceptable scientific standard, however I have significant reservations, as outlined above.

\section{Author Response 27 Jan 2018}

ahdieh chinekesh, University of Social Welfare \& Rehabilitation Sciences, Tehran, Iran

Dear chief editor of F1000research

Thanks for your comments. All of them have been considered in revised upload formatted carefully.

Ahdieh Chinekesh

Competing Interests: No competing interests were disclosed.

\section{Author Response 04 Feb 2018}

ahdieh chinekesh, University of Social Welfare \& Rehabilitation Sciences, Tehran, Iran

In the revised version of this article, we have included two sentences in the first paragraph of the 'Interviews' section, providing more detail on how they were conducted.

Competing Interests: No competing interests were disclosed.

The benefits of publishing with F1000Research:

- Your article is published within days, with no editorial bias

- You can publish traditional articles, null/negative results, case reports, data notes and more

- The peer review process is transparent and collaborative

- Your article is indexed in PubMed after passing peer review

- Dedicated customer support at every stage

For pre-submission enquiries, contact research@f1000.com 